\title{
Photodegradation profiles of PVC compound and wood/PVC composites under UV weathering
}

\author{
K. Chaochanchaikul ${ }^{1}$, V. Rosarpitak ${ }^{2}$, N. Sombatsompop ${ }^{1 *}$ \\ ${ }^{1}$ Polymer PROcessing and Flow (P-PROF) Group, School of Energy, Environment and Materials, King Mongkut's \\ University of Technology Thonburi (KMUTT), Bangmod, Thungkru, 10140 Bangkok, Thailand \\ ${ }^{2}$ V.P. Wood Co., Ltd., 25/5 Moo 4, Soi Suksawad 66, Bangmod, Thungkru, 10140 Bangkok, Thailand
}

Received 3 July 2012; accepted in revised form 19 September 2012

\begin{abstract}
This work aimed to study the effect of different ultraviolet (UV) weathering conditions (natural and accelerated) on the photodegradation of polyvinyl chloride (PVC) and wood/polyvinyl chloride (WPVC) composites by considering the structural and physical changes of PVC and WPVC samples as well as examining the photodegradation profiles at different depths from the sample surfaces. The photodegradation of PVC and WPVC composites under natural weathering conditions were lower than those under accelerated weathering conditions. The addition of Tinuvin P stabilizer at 2 phr was sufficient to stabilize PVC and WPVC composites, whereas the presence of wood appeared to accelerate the photodegradation of PVC under both natural and accelerated weathering conditions. When considering the photodegradation profiles at different depths of the samples, it was found that the polyene and carbonyl sequences of PVC and WPVC composites were high at the sample surfaces and tended to decrease rapidly with increasing depth from the specimen surface before stabilizing at a depth of $60 \mu \mathrm{m}$ for PVC and $80 \mu \mathrm{m}$ for WPVC composites. The differences in specimen depths for the stabilization of polyene and carbonyl sequences in PVC and WPVC samples implied that the presence of wood particles enhanced the absorption of UV radiation by the WPVC composite samples.
\end{abstract}

Keywords: polymer composites, wood, material testing, environmental degradation

\section{Introduction}

The use of WPC has been rapidly growing in several key market segments, such as outdoor decorations, and also building and construction products $[1,2]$. Therefore, evaluation of changes in the properties of WPC under service conditions has become a significant issue, as this indicates the durability of WPC products. Environmental factors - such as UV radiation from sunlight, and also moisture, temperature, and biological decay - result in chemical and physical changes to the structure of the material components in WPC.

Studies on the factors affecting on the properties of WPC under weathering conditions have focused on various aspects, such as weathering conditions (e.g. moisture, temperature, and biological decay) [320], wood content, processing method, weathering condition, and type and content of UV absorbers and pigments [3-14]. The presence of wood has been found to accelerate the photodegradation of WPC. Works by Stark and Matuana [3, 4] showed that wood particles accelerated the oxidation reaction at the surface of wood/high density polyethylene (WPE) composite, to a greater extent than that of neat high density polyethylene (HDPE). In the case of wood/polyvinyl chloride (WPVC) composites, the presence of wood strongly accelerated the photodegradation of PVC [5-7] and interfered with the function of a UV absorber [7]. The chromophore groups or carbonyl groups in lignin as a component

\footnotetext{
${ }^{*}$ Corresponding author, e-mail: narongrit.som@kmutt.ac.th (C) BME-PT
} 
of wood accelerated the photodegradation of polymer matrix with enhancing absorption of UV light on the WPC surface. Stark and Matuana [8] showed that WPC specimens processed by an extrusion method degraded more than the WPC specimen processed by an injection method. This was because the surface of the injection molded WPC have more of polymer rich layer when compared with that of the extruded WPC. A report by Wang et al. [9] indicated that a smooth WPC surface was more durable in terms of mechanical properties than a sawn WPC surface. The works of Stark and Matuana [8] and Wang et al. [9] implied that the emerged wood particles on the WPC surface accelerated the degradation in WPC.

Stark [10] studied the effect of weathering cycles on changes in color and mechanical properties of WPE composites, and found that exposure of WPE composites to water spray in combination with radiation in a xenon arc weathering apparatus was more severe than exposure to radiation alone. Filson et al. [11] studied the effect of weathering on chemical and color changes of WPVC composites, and found that the conjugated ketones and lignin were reduced by weathering, whereas the cellulose part was unaffected. The use of a UV absorber and/or pigment could improve the stabilization of the polymer matrix in WPC, which prevent or retard the photodegradation [7, 12-14]. In addition to UV radiation, moisture and temperature are classified as effective variables affecting the property changes in WPC. Moisture or water can accelerate photooxidation in WPC by causing swelling of the wood cell wall, thus facilitating light penetration into the wood [10]; this results in decreases in both strength and modulus of WPC due to the deterioration of interfacial bonding between natural fiber and matrix, and the softening of amorphous regions of microfibrils of wood fiber [10, 15, 16]. Bledzki et al. [17] found that the decrease of mechanical properties of wood/polypropylene (WPP) composites, after cyclic conditions of temperature and moisture, was partially reversible. However, cyclic conditions showed less effect than static conditions. The work of Wang et al. [18] indicated that the flexural strength and modulus of WPC tended to decrease significantly after freeze-thaw cycling treatment. Higher temperature was also found to increase the water absorption of WPC $[17,18]$.
Available literature indicates that there is very little information comparing the property changes of WPC under accelerated and natural conditions [21, 22]. Abu-Sharkh and Hamid [21] revealed that the photostability of maleic anhydride-grafted polypropylene (MAPP)-compatibilized palm fiber/PP composites under artificial weathering was higher than that under natural weathering. This was because the difference in light spectrum was produced by solar radiation, and that the accelerated weathering of MAPP was susceptible to degradation by radiation frequencies that were more abundant in solar radiation. The work of Fabiyi and McDonald [22] also reported on the effects of three weathering regimes - xenon-arc, UVA, and natural weathering - on the photodegradation of WPVC composites; they found that the carbonyl and polyene contents of weathered WPVC composites under xenon-arc and UVA weathering increased with increasing weathering time and then decreased after $1200 \mathrm{~h}$, whereas those under natural weathering progressively increased throughout the natural weathering times used.

Several studies have indicated that the degradation pattern of WPC under natural weathering might differ from that of WPC under accelerated weathering, based on laboratory conditions [21, 22]; also, a previous study [7] reported on the effect of the type and content of a UV stabilizer on the photostabilization of WPVC composites using a QUV weatherometer only. Therefore, it would be interesting to investigate the photodegradation pattern of WPVC composites under natural weathering compared to that of WPC under accelerated weathering. In addition, the photodegradation level of WPVC composites at different depths from the specimen surface may differ; this was investigated in order to clarify the magnitude of photodegradation in WPVC composites.

Thus, this work was divided into two parts. The first part was to compare the photodegradation of WPVC composites under both natural and QUV weathering, while the second part was to study the magnitude of photodegradation in WPVC composites at different depths from the specimen surface. Photodegradation of WPVC composites was mainly evaluated by discoloration and chemical and structural changes. 


\section{Experimental}

\subsection{Raw materials}

The ingredients of the PVC compound and composites are shown in Table 1.

\subsubsection{Suspension PVC}

Suspension PVC (trade name, SIAMVIC 258RB) was supplied by V.P. Wood Co., Ltd. (Bangkok Thailand). The PVC powder was dry-blended with various necessary additives as listed in Table 1, this being referred to as PVC compound.

\subsubsection{Wood flour particles}

Wood flour particles were supplied by V.P. Wood Co., Ltd. and were chemically treated with N-(2aminoethyl)-3-aminopropyl trimethoxysilane of $1.0 \mathrm{wt} \%$ wood flour. For silane treatment, the wood flour was dried in oven for $24 \mathrm{~h}$ at $80^{\circ} \mathrm{C}$ or until the weight of wood flour was constant to remove the moisture. The silane solution was prepared by dropping $\mathrm{N}$-(2-aminoethyl)-3-aminopropyl trimethoxysilane slowly into mixture of deionized water and $1 \%$ acetic acid. And then the silane solution was sprayed onto wood flour, with a better mixing obtained with a high speed mixer for 5 mins. Thereafter, the treated wood flour was oven-dried for $6 \mathrm{~h}$ at $100^{\circ} \mathrm{C}$ until a constant weight was achieved for the removal of the solvent. In this work, the content of wood flour in the PVC compounds varied: 0,50 or 100 parts per hundred resin [phr] of PVC powder.

\subsubsection{UV stabilizers}

From our previous work [7], 2-(2H-benzotriazol-2yl)-p-cresol (trade name, Tinuvin P; Ciba Specialty Chemicals, Basel, Switzerland) at 2 phr was recommended as the most effective UV stabilizer for both PVC and WPVC composites. Therefore, formulations of PVC and WPVC composites with $2 \mathrm{phr}$ of Tinuvin $\mathrm{P}$ were chosen to compare the effects of weathering regimes and the magnitude of photodegradation at different depths from the specimen surface. After weathering, changes in chemical structure and color of PVC and WPVC composites with 2 phr of Tinuvin $\mathrm{P}$ were examined.

\subsection{Sample preparation}

PVC and WPVC composites were produced by an industrial-scale twin-screw extruder (D-521; Reifenhäuser Extrusion GmbH, Troisdorf, Germany) with counter-rotating screws. The experimental proce-
Table 1. Materials formulations for PVC compound and WPVC composites

\begin{tabular}{|l|c|}
\hline \multicolumn{1}{|c|}{ Ingredients } & $\begin{array}{c}\text { Concentration } \\
\text { [phr] }\end{array}$ \\
\hline $\begin{array}{l}\text { Suspension PVC grade SIAMVIC } \\
(K \text { value }=58)\end{array}$ & 100.0 \\
\hline External lubricant (Finalux ${ }^{\circledR}$ G-741) & 0.6 \\
\hline Internal lubricant (Ca-St) & 0.6 \\
\hline Acrylic Processing aids (Kane Ace $\left.{ }^{(}\right)$PA-20) & 6.0 \\
\hline One pack heat stabilizer (PF608) & 3.6 \\
\hline Natural filler (wood flour) & Varied $(0,50,100)$ \\
\hline UV Stabilizers (Tinuvin P) & Varied $(0,1.0,2.0)$ \\
\hline
\end{tabular}

dure and instruments used for the sample preparation are detailed in our previous work [7]. The processing temperature profiles on the extruder from hopper to die zones were 170, 160, 150, 140, 135 and $170^{\circ} \mathrm{C}$. The screw rotating speed was $16 \mathrm{rpm}$. A slit die, whose dimensions (width $\times$ height $\times$ length) were $40 \times 4 \times 180 \mathrm{~mm}^{3}$, was used to produce slit extrudates. The extrudates were then solidified by passing through a water cooling-system before collection for preparing specimens.

\subsection{Effects of natural and accelerated weathering conditions \\ 2.3.1. QUV weathering testing}

PVC and WPVC specimens were cut from extrudates whose dimensions were dependent on the standard testing methods used. The prepared PVC and WPVC specimens were weathered in a QUV weatherometer (Q-Lab, Cleveland OH, USA) operated according to ASTM G154 (2006). PVC and WPVC specimens were UV-weathered under cyclic UV/condensation exposures: $8 \mathrm{~h}$ of UV light exposure at $60^{\circ} \mathrm{C}$ under $313 \mathrm{~nm}$ fluorescent UV (UVB) lamps, followed by $4 \mathrm{~h}$ of condensation temperatures at $50^{\circ} \mathrm{C}$ in dark condition (without UV exposure). The weathered PVC and WPVC specimens were evaluated for changes in chemical structure and color after UV weathering times of 0 to $720 \mathrm{~h}$.

\subsubsection{Natural weathering testing}

PVC and WPVC specimens were exposed on a roof deck at the School of Energy, Environment and Materials building at King Mongkut's University of Technology Thonburi, Bangkok, Thailand, for 365 days (from April 2010 through March 2011). The typical weather conditions in Bangkok for the duration of exposure are illustrated in Table 2. Data regarding average weather conditions were provided by the Thai Metrological Department. PVC and WPVC 
Table 2. Average weather conditions in Bangkok for April 2010 to March 2011

\begin{tabular}{|l|c|c|c|c|}
\hline \multicolumn{1}{|c|}{ Weather condition } & April - June 2010 & July - September 2010 & October - December 2010 & January - March 2011 \\
\hline Temperature $\left[{ }^{\circ} \mathrm{C}\right]$ & 31.03 & 28.93 & 27.86 & 27.47 \\
\hline Relative humidity $[\%]$ & 72.68 & 79.33 & 70.64 & 68.56 \\
\hline UV-B intensity $\left[\mathrm{W} / \mathrm{m}^{2}\right]$ & 0.36 & 0.33 & 0.24 & 0.24 \\
\hline Rainfall $[\mathrm{mm}]$ & 5.44 & 11.97 & 2.30 & 2.29 \\
\hline
\end{tabular}

specimens were placed on aluminum exposure racks according to ASTM D1435 (2005). The specimens were mounted on the racks at a $45^{\circ}$ angle, facing in a southerly direction, and were later taken for characterization after 90, 180, 270 and 365 days.

\subsection{Photodegradation profiles at different depths from the specimen surface}

PVC and WPVC specimens weathered by a QUV weatherometer at UV weathering times of 0 and $720 \mathrm{~h}$ were studied for their photo-degradation level at different depths from the specimen surface, using an abrasion tester to remove the weathered PVC and WPVC surface layers to the desired depth. Standard curves relating to the thickness of the removed specimen bulk and the number of abrasions were established for determination of the number of abrasions. The magnitude of photodegradation at different depths from the specimen surface were investigated based on structural changes, in terms of polyene and carbonyl sequences and color changes, as well as from visual photographs.

Standard curves were established as a plot of the number of abrasions against the thickness of the removed specimen surface. Removal of the specimen surface was performed using an abrasion tester (Taber Abraser model 5130; Testing Machines Inc., Ronkonkoma NY, USA). Sandpaper (P12) with an

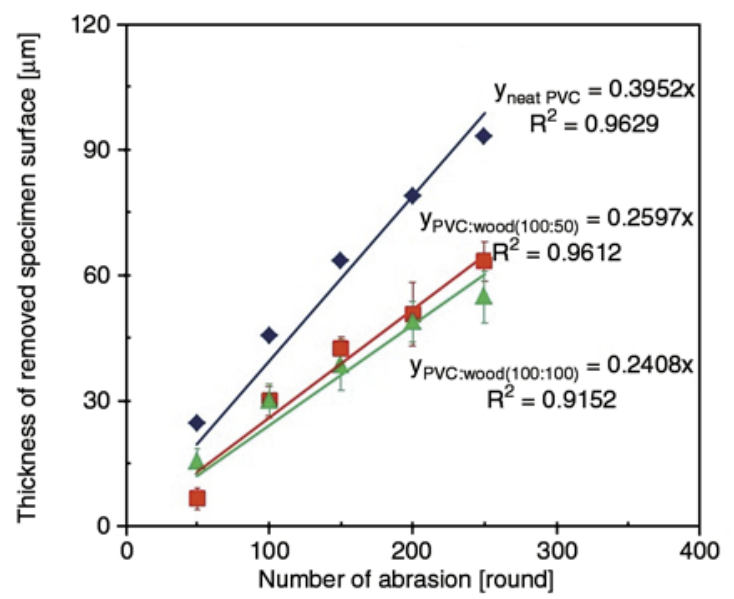

Figure 1. Standard curves between removed thickness of specimen surface and number of abrasions
Table 3. Number of abrasion for removing specimen surface at every $20 \mu \mathrm{m}$

\begin{tabular}{|l|c|}
\hline \multicolumn{1}{|c|}{ Formula } & Number of abrasion [round] \\
\hline PVC & 51 \\
\hline PVC with wood flour at $50 \mathrm{phr}$ & 77 \\
\hline PVC with wood flour at $100 \mathrm{phr}$ & 83 \\
\hline
\end{tabular}

average grit size of $1815 \mu \mathrm{m}$ was used for abrasion of specimen surfaces in the abrasion tester. The number of abrasions was varied from 50, 100, 150, 200 and 250 rounds and the thickness of the removed specimen was measured using a micrometer. During abrasion, each specimen was pressed with a $250 \mathrm{~g}$ steel load. The standard curves for PVC and for WPVC composites with wood contents of 50 and $100 \mathrm{phr}$ are given in Figure 1. The calculated number of abrasions for removing each $20 \mu \mathrm{m}$ of specimen surface is shown in Table 3 . The chemical structure and color of weathered PVC and WPVC composites at $720 \mathrm{~h} \mathrm{UV}$ weathering time were evaluated as a function of depth from specimen surface ranging from 0 to $100 \mu \mathrm{m}$ as compared to those of un-weathered PVC and WPVC composites.

\subsection{Characterizations}

It should be noted that all reported data for all tests were averaged from at least three independent specimens and each specimen was measured from at least three different positions.

\subsubsection{Contact angle measurement}

Contact angles of unweathered and weathered WPVC samples were measured using a contact angle goniometer (model 100-00; Ramé-Hart, Succasunna NJ, USA) equipped with an automated camera and image analysis software. Distilled water was used as the wetting liquid. Further details of the experimental procedure can be obtained elsewhere [23].

\subsubsection{Structural change analysis}

Polyene and carbonyl indices were determined using attenuated total reflectance-Fourier transform 
infrared (ATR-FTIR) analysis to assess the extent of degradation of the PVC and WPVC. A Nicolet 6700 FT-IR spectrometer (Thermo Scientific, Waltham MA, USA) was used to measure the reflectance spectra of specimens, as well as changes in their absorbance. Polyene and carbonyl indices were calculated in accordance with our previous work [7]. The wavenumbers of interest were 2920, 1650 and $1730 \mathrm{~cm}^{-1}$, representing $\mathrm{C}-\mathrm{H}$ stretching, polyene sequences and carbonyl groups, respectively.

\subsubsection{Discoloration testing}

Color changes of unweathered and weathered PVC and WPVC specimens were determined using two different color systems: Munsell and CIELAB. In the Munsell color system, the yellowness index (YI) was estimated using a UV-Vis spectrophotometer (model 3100; Shimadzu, Kyoto, Japan) under the standard source $\mathrm{C}$. The $Y I$ values of unweathered and weathered specimens were calculated in accordance with our previous work [24].

In addition, a UV-Vis spectrophotometer was used to measure color changes of PVC and WPVC samples before and after weathering, using the CIELAB color system. $L^{*} a^{*} b^{*}$ coordinates of unweathered and weathered PVC and WPVC specimens were calculated based on a D65 light source. $L^{*}$ represents the lightness, whereas $a^{*}$ and $b^{*}$ are the chromaticity coordinates. The total color changes or discolorations of the weathered specimens were calculated from differences of lightness and chromatic coordinates $(\Delta E)$ of unweathered and weathered $\mathrm{PVC}$ and WPVC specimens [25].

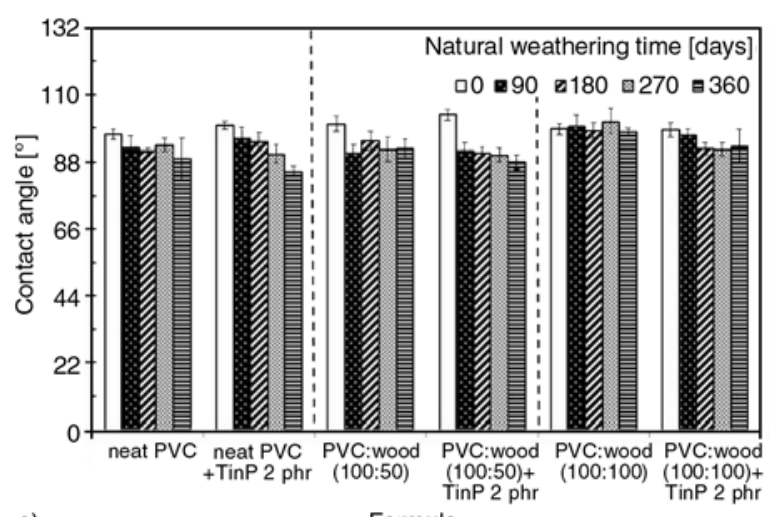

a)

Formula

\section{Results and discussion}

\subsection{Effects of natural and accelerated weathering conditions}

\subsubsection{Contact angle analysis}

Figure 2 shows contact angle values of PVC and WPVC composites with and without Tinuvin $\mathrm{P}$ at 2 phr under natural and QUV weathering conditions. It was found that the initial contact angle of PVC was slightly different from that of WPVC composites, suggesting that wood particles had no significant effect on the contact angle value. After weathering, the contact angle for PVC and WPVC composites generally decreased with increasing weathering time under both natural and QUV weathering conditions except for WPVC with wood content of $100 \mathrm{phr}$ under natural weathering, suggesting that the specimen surfaces of the PVC and WPVC composites became more hydrophilic. The decreases in contact angle with weathering time were more obvious in the case of QUV weathering, indicating that photodegradation of PVC and WPVC composites under QUV weathering became more severe than under natural weathering.

\subsubsection{Structural changes}

Figure 3 shows the effects of weathering conditions on the polyene index of PVC and WPVC composites with and without Tinuvin $\mathrm{P}$ at $2 \mathrm{phr}$. The polyene contents of PVC and WPVC composites under natural and QUV weathering conditions were found to increase with increasing weathering time. The change in the polyene index in the case of QUV weathering, however, was more pronounced than in the case of natural weathering. It is known that radi-

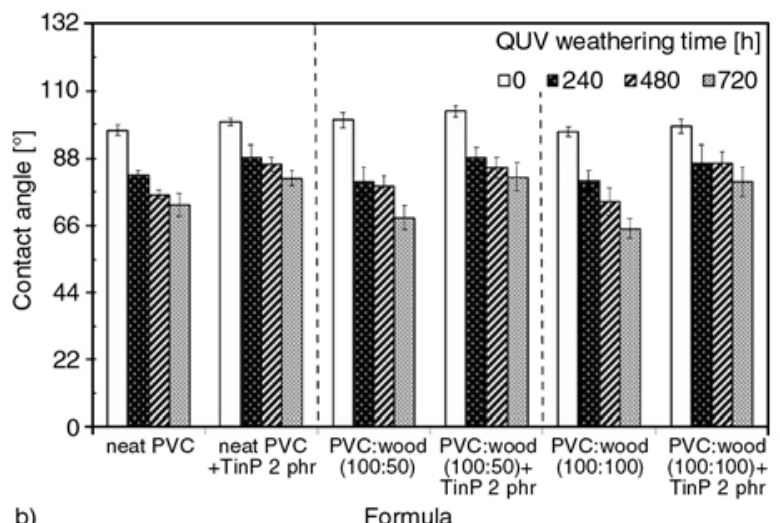

b)

Formula

Figure 2. Effect of weathering condition on contact angle in PVC and WPVC composites with and without Tinuvin P at 2 phr: (a) natural weathering condition, (b) QUV weathering condition 

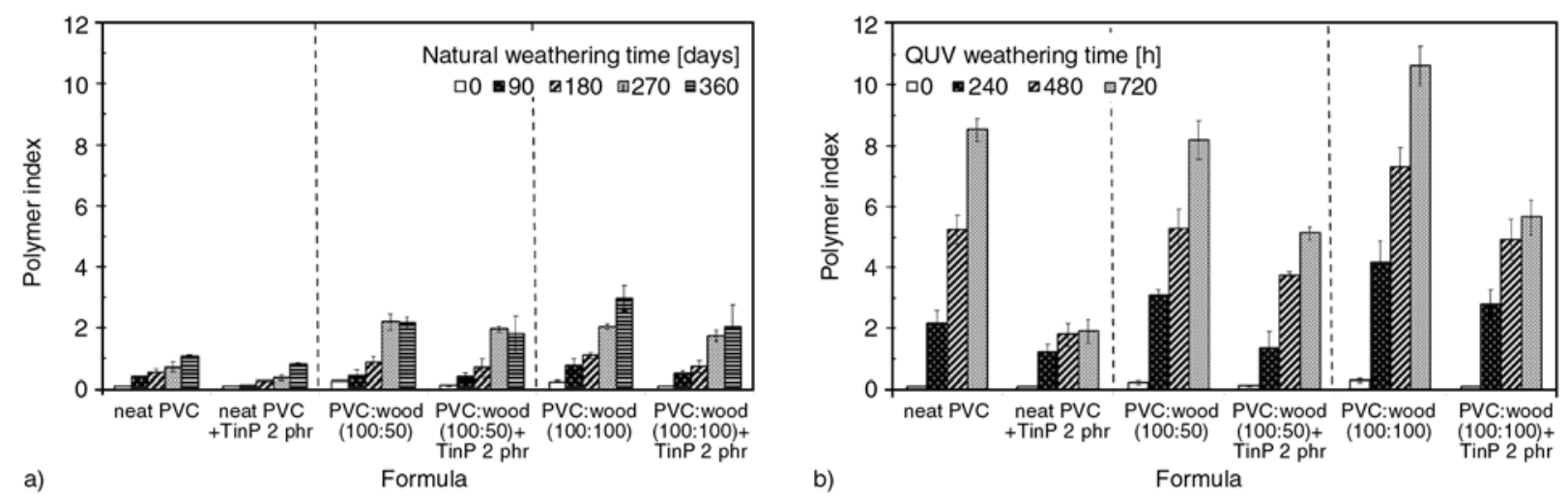

Figure 3. Polyene index in PVC and WPVC composites with and without Tinuvin P at 2 phr: (a) natural weathering condition, (b) QUV weathering condition

ation from sunlight under natural weathering conditions includes visible light, UV and infrared radiation, whereas the radiation from a UVB lamp under QUV weathering conditions contains only UV radiation (280-380 nm) [26]. In general, radiation in UV wavelengths is primarily responsible for PVC degradation [27]. In this case, UV radiation under natural weathering was much lower than that under QUV weathering. This was the reason for greater PVC degradation under QUV weathering as compared with natural weathering. The addition of Tinuvin P could stabilize PVC and WPVC composites, as seen by a decrease in polyene content; whereas the presence of wood appeared to accelerate the photodegradation of PVC under both natural and QUV weathering conditions. This was evidenced by an increase in polyene content with increasing wood content (from 50 to $100 \mathrm{phr}$ ). Figure 4 shows the carbonyl index as a function of weathering time of PVC and WPVC composites, with and without Tinuvin $\mathrm{P}$, under different weathering conditions. The carbonyl index of both PVC and WPVC composites tended to increase with weathering time under both natural and QUV weathering conditions

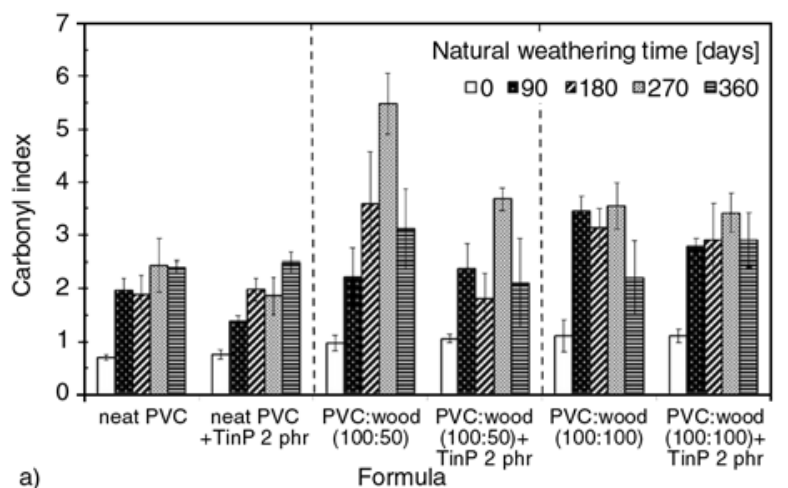

- except for WPVC under natural weathering, and WPVC with wood content of $100 \mathrm{phr}$ under QUV weathering. The increase in the carbonyl index was probably caused by the oxidation reaction of PVC, in both PVC compound and WPVC composites [22, 28]. In WPVC composites, the carbonyl content could increase and then decrease at longer weathering times, this being associated with the photodegradation of lignin, which reversibly transformed the paraquinone to hydroquinone structures [12]. In addition to the cause of photodegradation in lignin, the decrease of carbonyl index for the WPVC specimen under natural weathering may be because the outer layer of the weathered specimens was washed away by rain. For the effect of weathering conditions, it was observed that the changes of carbonyl content under natural weathering was lower than those under QUV weathering, the explanation being similar to the polyene results. The addition of Tinuvin $\mathrm{P}$ at $2 \mathrm{phr}$ was found to reduce the photooxidation of PVC and WPVC composites under both natural and QUV weathering conditions, as evidenced by a decrease in the carbonyl index as compared with the specimens without Tinuvin P.

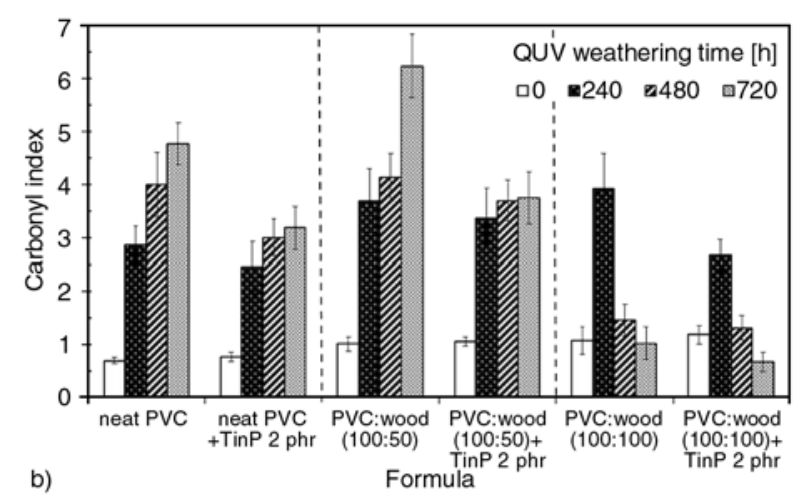

Figure 4. Carbonyl index in PVC and WPVC composites with and without Tinuvin P at 2 phr: (a) natural weathering condition, (b) QUV weathering condition 


\subsubsection{Discoloration}

Figure 5 shows $Y I$ of PVC and WPVC composites with and without Tinuvin $\mathrm{P}$ under different weathering conditions. The effect of natural and QUV weathering conditions on $Y I$ of PVC and WPVC specimens was found to be different. For natural weathering, $Y I$ of $\mathrm{PVC}$ without Tinuvin $\mathrm{P}$ did not change with increasing weathering time, whereas that of PVC with Tinuvin $P$ tended to decrease at 90 days after that did not change. The decrease of YI of PVC was probably because the coloration of PVC changed from yellow-white to light gray; this is known as the 'whitening effect', which is caused by visible radiation at wavelengths above $400 \mathrm{~nm}$ [29]. A similar whitening effect of PVC was also mentioned in the report by Real et al. [30]. The whitening effect of PVC was because the attack of oxygen on long polyenes molecules, resulting in the reduction in values in case of PVC without Tinuvin $\mathrm{P}$ and PVC with Tinuvin $\mathrm{P}$ after weathering time of 90 days may be a result photoyellowing of PVC caused by $\mathrm{UV}$ radiation that compensated for the photobleaching of PVC by visible radiation. For WPVC compos-

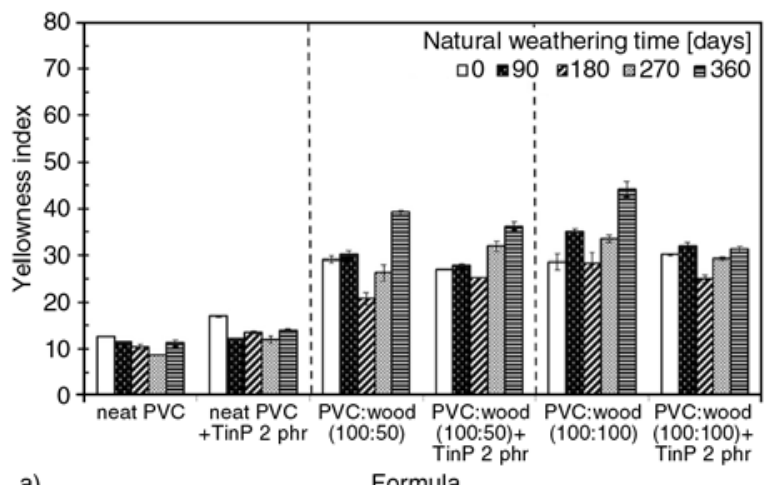

a) Formula polyene length [31]. However, the unchanged $Y I$

ite under natural weathering, $Y I$ values increased at weathering time of 90 days and then decreased at 180 days and increased again at 270 days. The increase of $Y I$ at initial weathering time was probably affected by wash-away by rain, which led to a color change from brown to yellow shade. The decrease of $Y I$ at 180 days might be attributed to photobleaching of PVC as discussed for neat PVC. The increase of $Y I$ at 270 days was again caused by an obvious photoyellowing of PVC. For QUV weathering, $Y I$ of both PVC and WPVC composites increased with increasing QUV weathering time except for that of PVC adding Tinuvin $\mathrm{P}$ did not change after weathering time of $240 \mathrm{~h}$. The increase of $Y I$ of both PVC and WPVC composites under QUV weathering resulted from the photoyellowing of PVC caused by intense UV radiation. The addition of Tinuvin $\mathrm{P}$ could diminish the change in $Y I$ under both natural and QUV weathering especially for PVC. This explanation of YI corresponds well to the visual photographs of PVC and WPVC composites under natural and QUV weathering conditions (Figure 6).

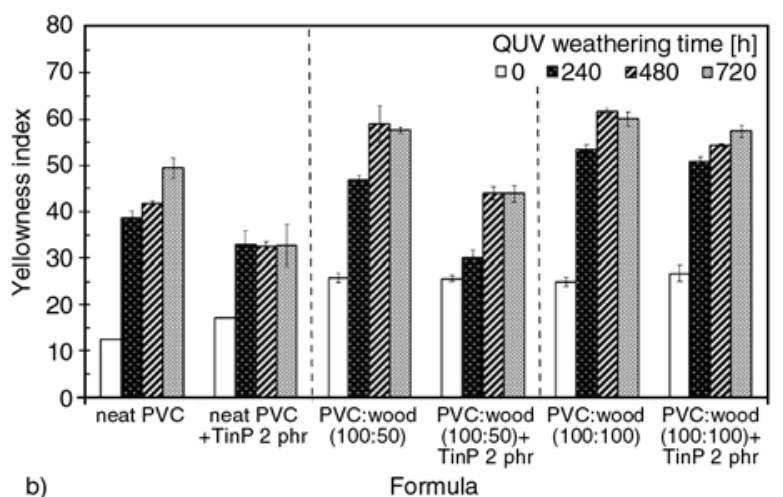

Figure 5. Effect of weathering condition on yellowness index in PVC and WPVC composites with and without Tinuvin P at 2 phr: (a) Natural weathering condition, (b) QUV weathering condition

\begin{tabular}{|c|c|c|c|c|c|c|}
\hline $\begin{array}{c}\text { Natural } \\
\text { weathering } \\
\text { time } \\
\text { [days] }\end{array}$ & $\begin{array}{c}\text { neat } \\
\text { PVC }\end{array}$ & $\begin{array}{c}\text { neat PVC } \\
\text { TinP 2 phr }\end{array}$ & $\begin{array}{c}\text { PVC:wood } \\
\text { (100:50) }\end{array}$ & $\begin{array}{l}\text { PVC:wood } \\
\text { (100:50) } \\
\text { TinP 2 phr }\end{array}$ & $\begin{array}{l}\text { PVC:wood } \\
(100: 100)\end{array}$ & $\begin{array}{l}\text { PVC:wood } \\
\text { (100:100) } \\
\text { TinP 2 phr }\end{array}$ \\
\hline 0 & & & & & & \\
\hline 90 & & & & & & \\
\hline 180 & & & & & & \\
\hline 270 & & & & & & \\
\hline 360 & & & & & & \\
\hline
\end{tabular}

\begin{tabular}{|c|l|c|c|c|c|c|}
\hline $\begin{array}{c}\text { QUV } \\
\text { weathering } \\
\text { time } \\
{[\text { [h] }}\end{array}$ & $\begin{array}{c}\text { neat } \\
\text { PVC }\end{array}$ & $\begin{array}{c}\text { neat PVC } \\
\text { TinP 2 phr }\end{array}$ & $\begin{array}{c}\text { PVC:wood } \\
(100: 50)\end{array}$ & $\begin{array}{l}\text { PVC:wood } \\
(100: 50) \\
\text { TinP 2 phr }\end{array}$ & $\begin{array}{l}\text { PVC: wood } \\
(100: 100)\end{array}$ & $\begin{array}{c}\text { PVC: wood } \\
\text { (100:100) } \\
\text { TinP 2 phr }\end{array}$ \\
\hline 0 & & & & & & \\
\hline 240 & & & & & & \\
\hline 480 & & & & & & \\
\hline 720 & & & & & & \\
\hline
\end{tabular}

b)

Figure 6. Digital photographs of PVC and WPVC composites with and without Tinuvin P at 2 phr: (a) natural weathering condition, (b) QUV weathering condition 

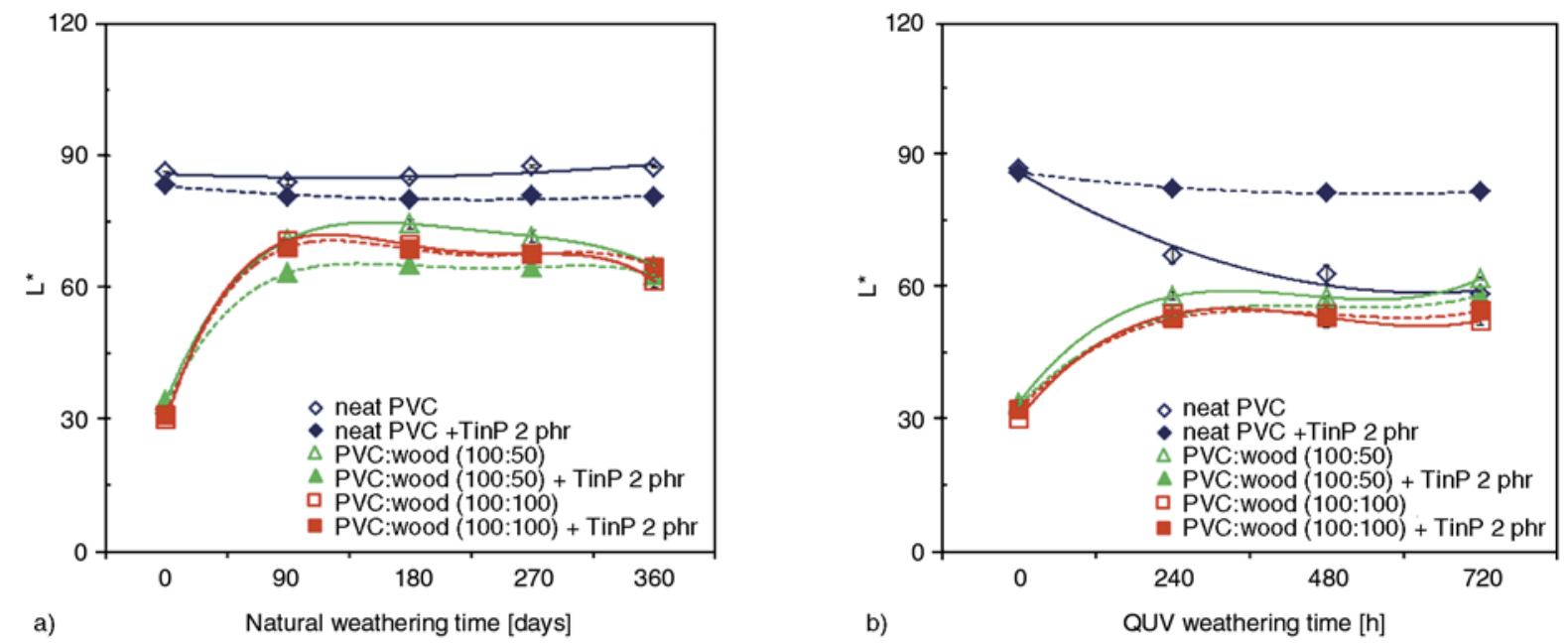

Figure 7. Effect of weathering condition on lightness in PVC and WPVC composites with and without Tinuvin P at 2 phr: (a) natural weathering condition, (b) QUV weathering condition

Figure 7 shows $L^{*}$ as a function of weathering time for PVC and WPVC composites, with and without Tinuvin $\mathrm{P}$ at $2 \mathrm{phr}$, under natural and QUV weathering conditions. It was observed that $L^{*}$ of $\mathrm{PVC}$, with and without Tinuvin P, slightly changed with weathering time under natural and QUV weathering conditions - except for PVC without Tinuvin P under QUV weathering, in which $L^{*}$ tended to decrease when subjected to UV weathering. This resulted from photoyellowing of PVC under severe UV conditions and without a UV stabilizer. $L^{*}$ for WPVC composites, with and without Tinuvin $\mathrm{P}$, and under both natural and QUV weathering, increased at initial weathering time and leveled off after 90 days and $240 \mathrm{~h}$ for natural and QUV weathering, respectively. The increases of $L^{*}$ for WPVC composites indicated that the photobleaching effect of lignin was more predominant than the photodegradation

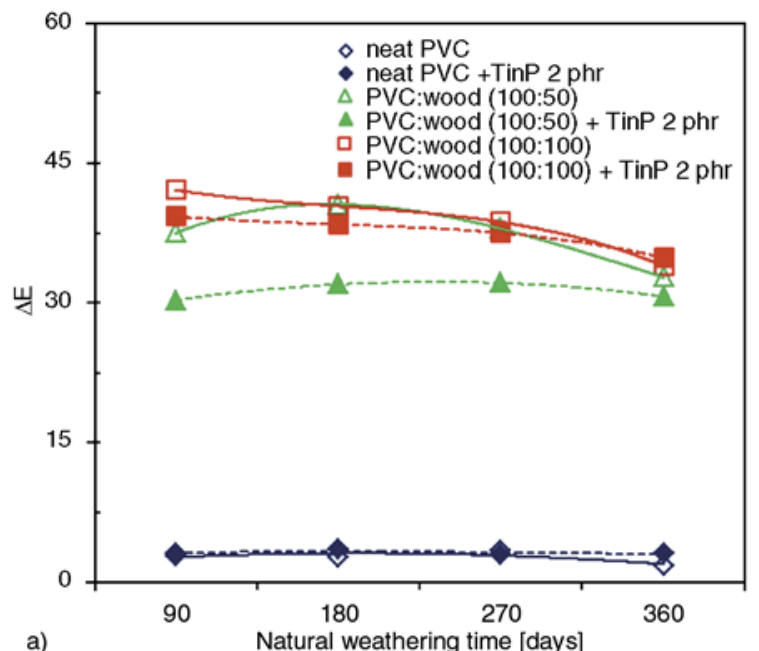

effect of PVC in WPVC composites. $L^{*}$ values for weathered WPVC composites under natural weathering conditions were higher than those of weathered WPVC composites under QUV weathering conditions. This was because natural rainwater removes some water-soluble extractives that impart color to wood flour [8]. In addition, chromophores in lignin enhance the absorption of visible light on the specimen surface [32]; this may lead to the whitening effect of the PVC in WPVC composites.

The total discoloration $(\Delta E)$ values under natural and QUV weathering conditions are given in Figure 8. It was found that the $\Delta E$ values of PVC under natural weathering were lower than those of PVC under accelerated weathering, whereas those of the WPVC composites exhibited the opposite trend. The lower $\Delta E$ values of PVC under natural weathering occurred because the degradation of PVC

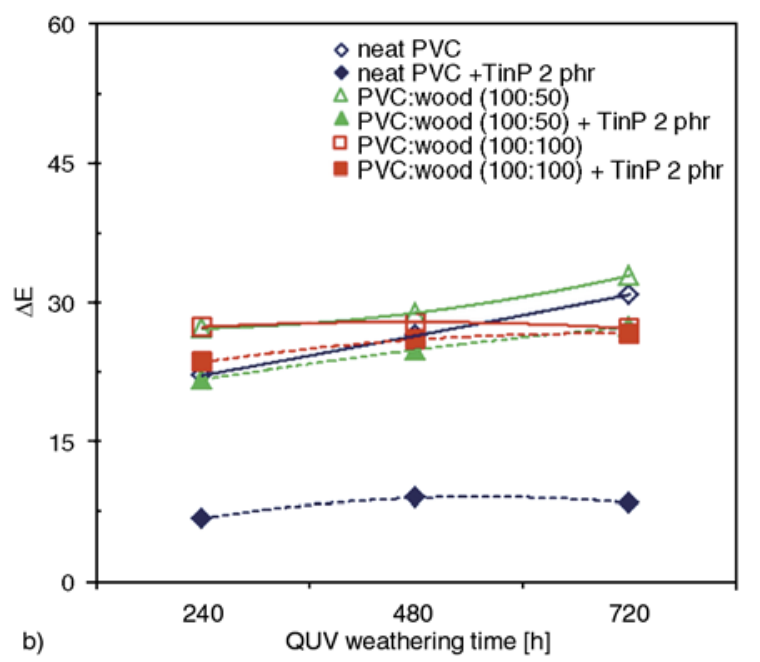

Figure 8. Effect of weathering condition on discoloration in PVC and WPVC composites with and without Tinuvin P at 2 phr: (a) natural weathering condition, (b) QUV weathering condition 
caused by solar radiation was much lower than that caused by UV radiation in a QUV weatherometer. Higher $\Delta E$ values of WPVC composites under natural weathering might be attributed to the photobleaching of both PVC and wood flour during natural weathering tests, whereas those of WPVC composites under QUV weathering were affected by photobleaching of lignin and photoyellowing of PVC. The photobleaching of lignin in WPVC composites under QUV weathering was partially compensated by the photoyellowing of PVC during QUV weathering testing.

In regard to the effect of Tinuvin $P$, it was found that Tinuvin $\mathrm{P}$ could improve the photostability of both PVC and WPVC composites under both natural and QUV weathering conditions, as seen by a reduction of $\Delta E$ values with the addition of Tinuvin P. However, the differences in $\Delta E$ values of PVC with and without Tinuvin $\mathrm{P}$ under natural weathering conditions were not evident over the natural weathering time of 365 days due to the small amount of PVC degradation. In WPVC composites, the differences
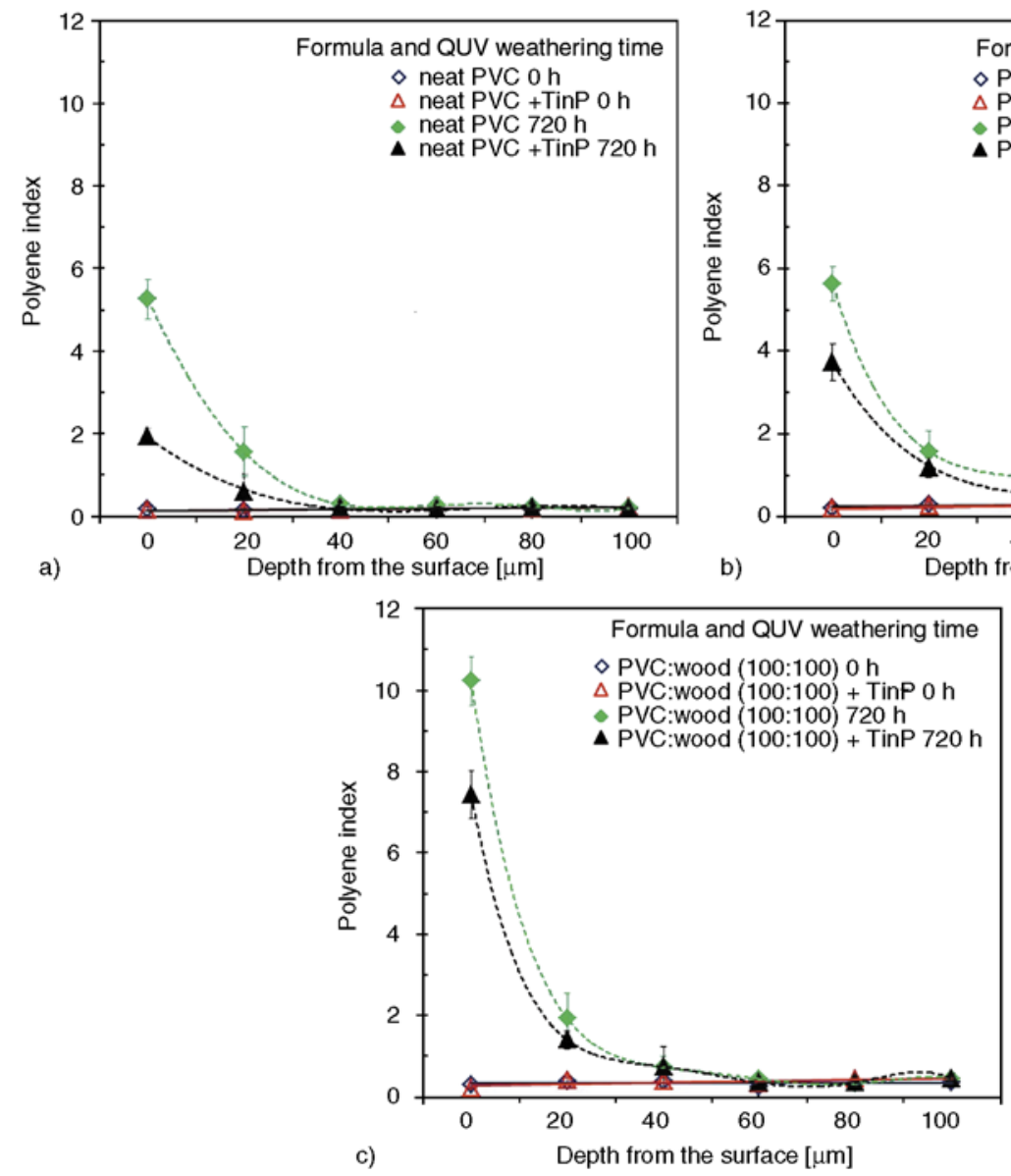

Figure 9. Polyene index as a function of depth from the surface for PVC and WPVC composites with and without 2 phr Tinuvin $\mathrm{P}$ at weathering times of 0 and $720 \mathrm{~h}$ : (a) neat PVC, (b) PVC with wood flour at $50 \mathrm{phr}$, (c) PVC with wood flour at $100 \mathrm{phr}$ in $\Delta E$ values of WPVC composites with and without Tinuvin $\mathrm{P}$ under natural weathering conditions were greater than those under QUV weathering conditions; this was because Tinuvin $\mathrm{P}$ could stabilize PVC in WPVC composites under natural weathering, resulting in a reduction of photobleaching (less color fading) of the PVC. The addition of Tinuvin P under QUV weathering conditions also led to a reduction in photoyellowing of PVC in WPVC composites.

\subsection{Photodegradation profiles at different depths from specimen surface}

\subsubsection{Structural changes}

The profiles of polyene and carbonyl indices at various depths from the specimen surfaces for unweathered and QUV-weathered PVC and WPVC composites with and without $2 \mathrm{phr}$ Tinuvin $\mathrm{P}$ are shown in Figures 9 and 10, respectively. The depth from the specimen surface was contingent on the abrasion number of sandpaper. The polyene and carbonyl contents of weathered PVC and WPVC composites

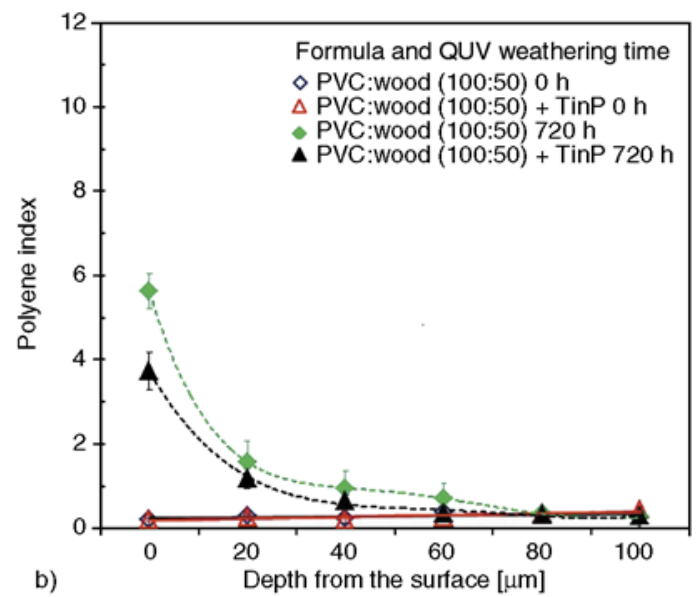



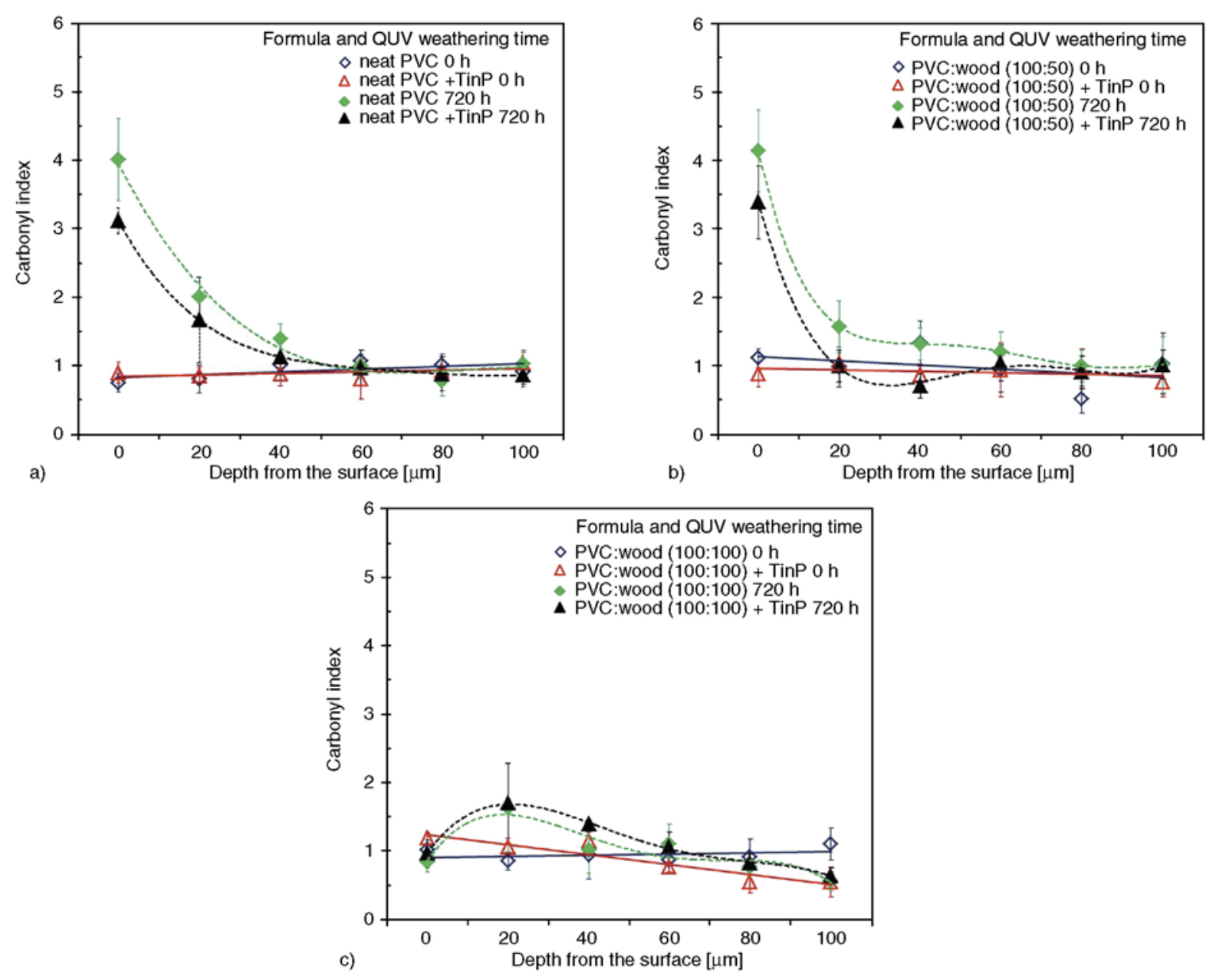

Figure 10. Carbonyl index as a function of depth from the surface for PVC and WPVC composites with and without 2 phr Tinuvin P at QUV weathering times of 0 and 720 h: (a) neat PVC, (b) PVC with wood flour at 50 phr, (c) PVC with wood flour at $100 \mathrm{phr}$

at $720 \mathrm{~h}$ significantly decreased with increasing depth from the specimen surface, except for carbonyl content in WPVC with wood content of $100 \mathrm{phr}$; whereas those of unweathered PVC and WPVC composites remained unchanged. The polyene and carbonyl contents for weathered specimens significantly decreased at a depth of $20 \mu \mathrm{m}$ from the specimen surface, and then slightly decreased at further depths until stabilizing to an extent similar to those of unweathered PVC and WPVC composites, at 40-60 and 60-80 $\mu \mathrm{m}$, respectively. This result indicated that UV radiation could not penetrate PVC and WPVC specimens at thicknesses beyond 60 and $80 \mu \mathrm{m}$, respectively, and also that the presence of wood enhanced the absorption of UV radiation onto the WPVC surface resulting from increasing depth of UV penetration. However, the contents of polyene and carbonyl decreased with increasing depth from the specimen surface, and were more pronounced when the wood content was increased. The addition of Tinuvin P could improve the photostability of PVC in neat PVC and WPVC composites, as evidenced by decreases in the polyene and carbonyl indices of weathered PVC and WPVC composites. The polyene content of WPVC composites resulted from the photodegradation of PVC in WPVC composites, whereas the carbonyl contents for WPVC composites may have been caused by photooxidation of both PVC and lignin in WPVC composites.

\subsubsection{Discoloration}

$Y I$ profiles at various depths from the specimen surfaces of unweathered and QUV- weathered PVC and WPVC composites, with and without Tinuvin $\mathrm{P}$ at $2 \mathrm{phr}$, are shown in Figure 11. YI values of unweathered PVC remained unchanged despite increasing depth from the specimen surface, whereas those of unweathered WPVC composites with wood content of 50 and $100 \mathrm{phr}$ decreased at a depth up to $20 \mu \mathrm{m}$. The decreases in $Y I$ of WPVC composites at depths 

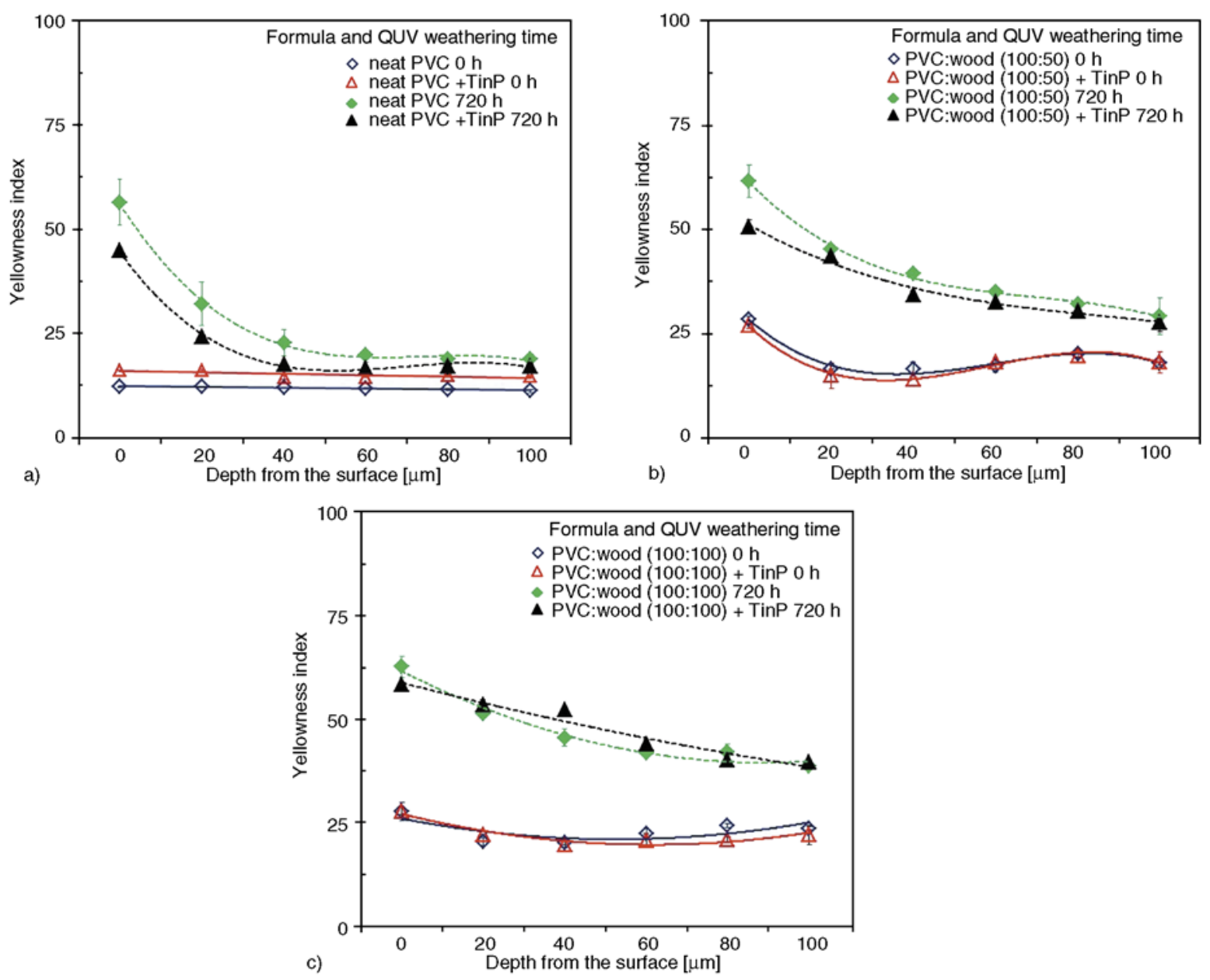

Figure 11. Yellowness index as a function of depth from the surface for PVC and WPVC composites with and without 2 phr Tinuvin P at QUV weathering times of 0 and 720 h: (a) neat PVC, (b) PVC with wood flour at 50 phr, (c) PVC with wood flour at $100 \mathrm{phr}$

between 0 and $20 \mu \mathrm{m}$ were caused by a white scratch occurring as a result of physical abrasion from sandpaper during the experiment, as shown in Figure 12. For QUV-weathered specimens, the YI val- ues for both PVC and WPVC composites decreased with increasing depth from the specimen surface, and then slightly changed at depths between 40 and $60 \mu \mathrm{m}$, respectively. However, the $Y I$ values of

\begin{tabular}{|c|c|c|c|c|c|c|c|c|c|c|c|c|}
\hline \multirow{3}{*}{$\begin{array}{l}\text { Depth } \\
\text { from } \\
\text { surface } \\
{[\mu \mathrm{m}]}\end{array}$} & \multicolumn{4}{|c|}{ neat PVC } & \multicolumn{4}{|c|}{ PVC:wood (100:50) } & \multicolumn{4}{|c|}{ PVC:wood (100:100) } \\
\hline & \multicolumn{2}{|c|}{ no UV stabilizer } & \multicolumn{2}{|c|}{ TinP 2 phr } & \multicolumn{2}{|c|}{ no UV stabilizer } & \multicolumn{2}{|c|}{ TinP $2 \mathrm{phr}$} & \multicolumn{2}{|c|}{ no UV stabilizer } & \multicolumn{2}{|c|}{ TinP 2 phr } \\
\hline & $\mathrm{Oh}$ & $720 \mathrm{~h}$ & $\mathrm{Oh}$ & $720 \mathrm{~h}$ & $\mathrm{Oh}$ & $720 \mathrm{~h}$ & $\mathrm{Oh}$ & $720 \mathrm{~h}$ & $\mathrm{Oh}$ & $720 \mathrm{~h}$ & $\mathrm{Oh}$ & $720 \mathrm{~h}$ \\
\hline 0 & & & & & & & & & & & & \\
\hline 20 & & & & & & & & & & & & \\
\hline 40 & & & & & & & 58 & & & & & \\
\hline 60 & & & & & & & & & & & & \\
\hline 80 & & & & & & & & & & & & \\
\hline 100 & & & & & & & & & & & & \\
\hline
\end{tabular}

Figure 12. Digital photographs of PVC and WPVC composites with wood contents of 50 and 100 phr, at QUV weathering times of 0 and $720 \mathrm{~h}$, at different depths from the specimen surface 
weathered specimens after abrasion still differed from those of unweathered specimens, especially in the case of WPVC composites. The difference in $Y I$ of PVC might be attributed to the thermal degradation of PVC caused by heat during QUV testing; whereas the difference for WPVC composites was mainly due to moisture, which removed some water-soluble extractives that imparted color to the wood flour [8]. Visual photographs of unweathered and weathered PVC and WPVC composites at various depths from the specimen surface are shown in Figure 12. It was found that color changes of PVC and WPVC specimens at different depths from the specimen surface corresponded well to the $Y I$ results. The $L^{*}$ profiles at different depths from the specimen surface for PVC and WPVC composites, with and without Tinuvin $\mathrm{P}$ and before and after QUV weathering of $720 \mathrm{~h}$, are shown in Figure 13. Similar to the $Y I$ values in Figure 11, the $L^{*}$ values of unweathered PVC remained unchanged with increas-

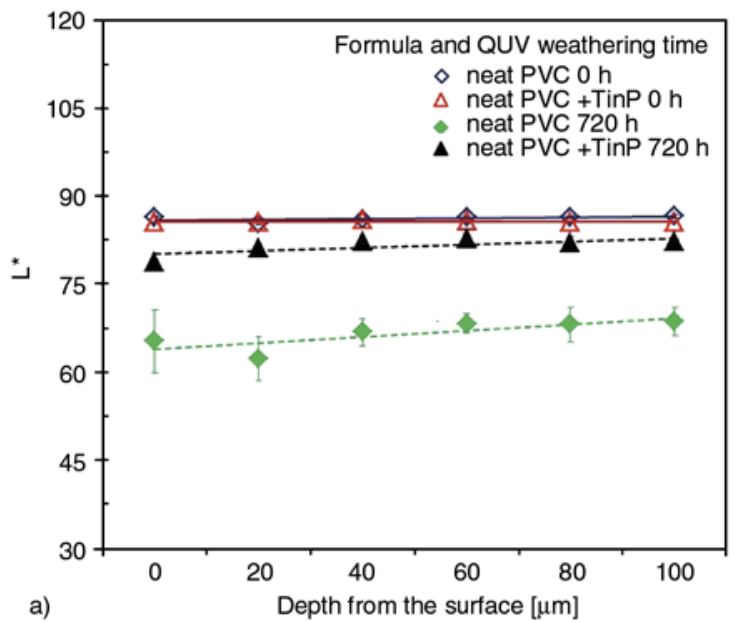

ing depth from the specimen surface, whereas those of unweathered WPVC composites increased at initial depth and then remained unchanged beyond $40 \mu \mathrm{m}$ depth. In the case of weathered specimens, the $L^{*}$ values of weathered PVC and WPVC specimens after abrasion differed from those of unweathered specimens. The differences in $L^{*}$ values can be explained in similar fashion, as given in Figures 11 and 12. The discolorations or total color changes $(\Delta E)$ in Figure 14 were determined from the differences of $L^{*}, a^{*}$ and $b^{*}$ values between unweathered and QUV-weathered specimens at identical depths from the specimen surface. It was found that the lower the $\Delta E$ values, the higher the depth from the specimen surface for both PVC and WPVC composites. The $\Delta E$ values of PVC and WPVC composites slightly changed beyond depths of 40 and $60 \mu \mathrm{m}$, respectively. Based on $\Delta E$ results, Tinuvin $\mathrm{P}$ appeared to be more effective in the stabilization of $\mathrm{PVC}$ as compared with WPVC composites.

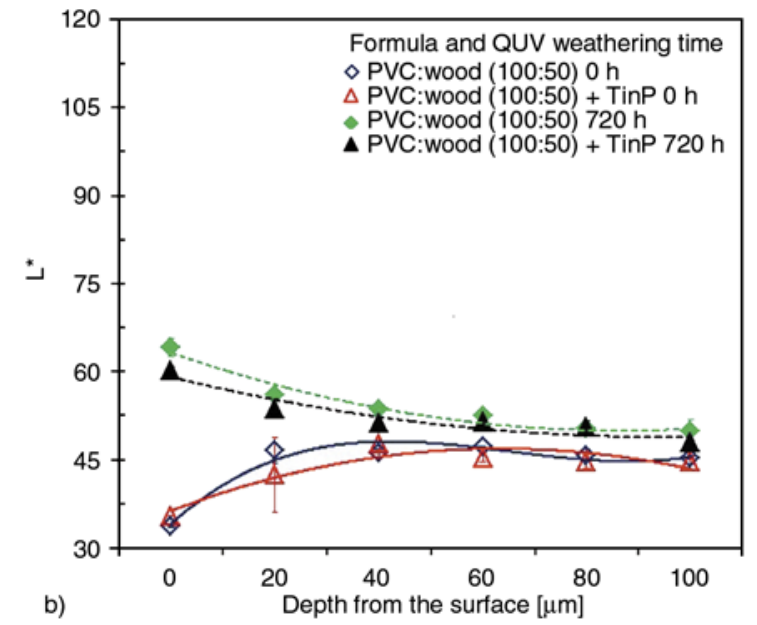

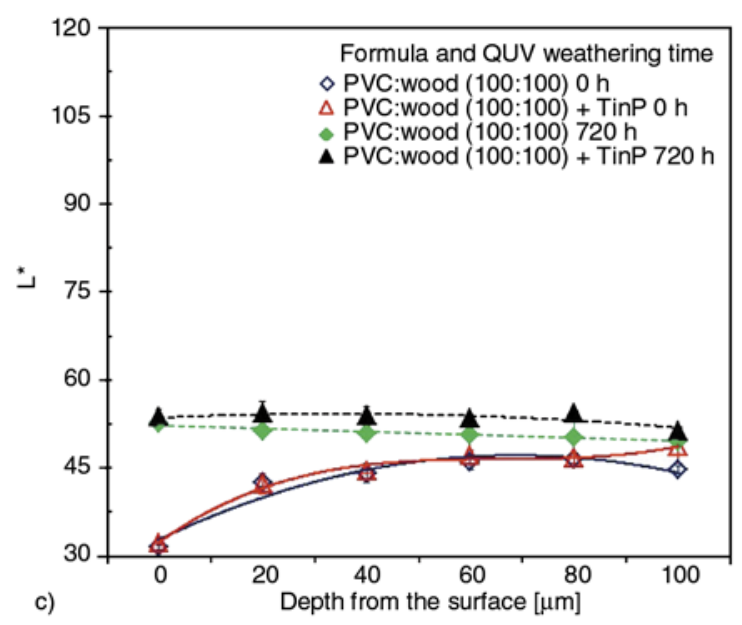

Figure 13. Lightness as a function of depth from the surface for PVC and WPVC composites with and without 2 phr Tinuvin P at QUV weathering times of 0 and 720 h: (a) neat PVC, (b) PVC with wood flour at 50 phr, (c) PVC with wood flour at $100 \mathrm{phr}$ 


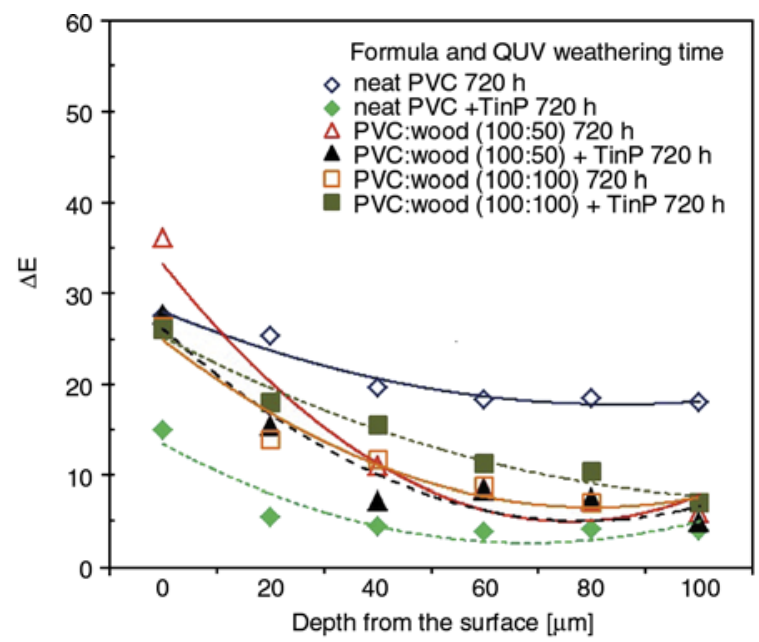

Figure 14. Discoloration levels of QUV-weathered PVC and WPVC composites, with and without $2 \mathrm{phr}$ Tinuvin P, compared with unweathered specimens at various depths from the specimen surface

\section{Conclusions}

The effects of different UV weathering conditions (natural and accelerated) on the photodegradation behavior of PVC and wood/polyvinyl chloride (WPVC) composites were studied and the following conclusions were noted.

- Changes in the polyene and carbonyl sequences and contact angle of PVC and WPVC composites under accelerated UV weathering were more pronounced than those under natural weathering. The addition of Tinuvin $\mathrm{P}$ could stabilize PVC and WPVC composites, whereas the presence of wood appeared to accelerate the photodegradation of PVC under both natural and QUV weathering conditions.

- The yellowness index of PVC and WPVC composites under natural weathering decreased with weathering time, but the opposite was observed for accelerated weathering conditions due to photobleaching of PVC under visible radiation.

- The lightness of WPVC composites under natural weathering conditions significantly increased as compared with accelerated weathering conditions due to the photobleaching effect on both PVC and wood parts.

- The polyene and carbonyl sequences of PVC and WPVC composites were high at the sample surfaces and then reduced significantly with increasing depth from the specimen surface before lev- eling off at the depth of $60 \mu \mathrm{m}$ for PVC and at $80 \mu \mathrm{m}$ for WPVC composite. The differences in the specimen depths to the stabilizations of polyene and carbonyl sequences in PVC and WPVC samples implied that the presence of wood particles enhanced the absorption of UV radiation onto the WPVC composite samples.

- The colors of PVC and WPVC composites after abrasion were different from unweathered specimens due to thermal degradation of PVC and color fading of the wood.

\section{Acknowledgements}

The authors would like to express their thanks to the Thailand Research Fund (TRF) under Senior Scholar Grant (RTA 5580009) for financial support of this work. The authors also are grateful to the Office of the Higher Education Commission (OHEC) for additional funding under the National Research University (NRU) program.

\section{References}

[1] Deng Y., Tang Y.: Increasing load-bearing capacity of wood-plastic composites by sandwiching natural and glass fabrics. Journal of Reinforced Plastics and Composites, 29, 3133-3148 (2010).

DOI: $10.1177 / 0731684410367535$

[2] Fabiyi J. S., McDonald A. G.: Effect of wood species on property and weathering performance of wood plastic composites. Composites Part A: Applied Science and Manufacturing, 41, 1434-1440 (2010).

DOI: $10.1016 /$ j.compositesa.2010.06.004

[3] Stark N. M., Matuana L. M.: Surface chemistry changes of weathered HDPE/wood-flour composites studied by XPS and FTIR spectroscopy. Polymer Degradation and Stability, 86, 1-9 (2004).

DOI: $10.1016 /$ j.polymdegradstab.2003.11.002

[4] Stark N. M., Matuana L. M.: Surface chemistry and mechanical property changes of wood-flour/high-density-polyethylene composites after accelerated weathering. Journal of Applied Polymer Science, 94, 22632273 (2004).

DOI: $10.1002 /$ app.20996

[5] Matuana L. M., Kamdem D. P., Zhang J.: Photoaging and stabilization of rigid PVC/wood-fiber composites. Journal of Applied Polymer Science, 80, 1943-1950 (2001).

DOI: $10.1002 / a p p .1292$

[6] Abu Bakar A., Hassan A., Mohd Yusof A. F.: Effect of accelerated weathering on the mechanical properties of oil palm empty fruit bunch filled UPVC composites. Iranian Polymer Journal, 14, 627-635 (2005). 
[7] Chaochanchaikul K., Sombatsompop N.: Stabilizations of molecular structures and mechanical properties of PVC and wood/PVC composites by Tinuvin and $\mathrm{TiO}_{2}$ stabilizers. Polymer Engineering and Science, 51, 1354-1365 (2011).

DOI: $10.1002 /$ pen. 21893

[8] Stark N. M., Matuana L. M.: Characterization of weathered wood-plastic composite surfaces using FTIR spectroscopy, contact angle, and XPS. Polymer Degradation and Stability, 92, 1883-1890 (2007).

DOI: $10.1016 /$ j.polymdegradstab.2007.06.017

[9] Wang W., Wang Q., Dang W.: Durability of a ricehull-polyethylene composite property change after exposed to UV weathering. Journal of Reinforced Plastics and Composites, 28, 1813-1822 (2009).

DOI: $10.1177 / 0731684408090574$

[10] Stark N. M.: Effect of weathering cycle and manufacturing method on performance of wood flour and highdensity polyethylene composites. Journal of Applied Polymer Science, 100, 3131-3140 (2006).

DOI: $10.1002 / a p p .23035$

[11] Filson P., Dawson-Andoh B. E., Matuana L.: Colorimetric and vibrational spectroscopic characterization of weathered surfaces of wood and rigid polyvinyl chloride-wood flour composite lumber. Wood Science and Technology, 43, 669-678 (2009).

DOI: $10.1007 / \mathrm{s} 00226-009-0254-5$

[12] Muasher M., Sain M.: The efficacy of photostabilizers on the color change of wood filled plastic composites. Polymer Degradation and Stability, 91, 1156-1165 (2006).

DOI: 10.1016/j.polymdegradstab.2005.06.024

[13] Du H., Wang W., Wang Q., Zhang Z., Sui S., Zhang Y.: Effects of pigments on the UV degradation of woodflour/HDPE composites. Journal of Applied Polymer Science, 118, 1068-1076 (2010).

DOI: 10.1002/app.32430

[14] Zhang Z-M., Du H., Wang W-H., Wang Q-W.: Property changes of wood-fiber/HDPE composites colored by iron oxide pigments after accelerated UV weathering. Journal of Forestry Research, 21, 59-62 (2010). DOI: 10.1007/s11676-010-0009-Z

[15] Bledzki A. K., Letman M., Viksne A., Rence L.: A comparison of compounding processes and wood type for wood fibre-PP composites. Composites Part A: Applied Science and Manufacturing, 36, 789-797 (2005). DOI: 10.1016/j.compositesa.2004.10.029

[16] Bengtsson M., Stark N. M., Oksman K.: Durability and mechanical properties of silane cross-linked wood thermoplastic composites. Composites Science and Technology, 67, 2728-2738 (2007).

DOI: $10.1016 /$ j.compscitech.2007.02.006

[17] Bledzki A. K., Letman-Sakiewicz M., Murr M.: Influence of static and cyclic climate condition on bending properties of wood plastic composites (WPC). Express Polymer Letters, 4, 364-372 (2010). DOI: $10.3144 /$ expresspolymlett.2010.46
[18] Wang W. H., Wang Q. W., Xiao H., Morrell J. J.: Effects of moisture and freeze-thaw cycling on the quality of rice-hull-PE composite. Pigment and Resin Technology, 36, 344-349 (2007). DOI: $10.1108 / 03699420710831764$

[19] Schirp A., Wolcott M. P.: Influence of fungal decay and moisture absorption on mechanical properties of extruded wood-plastic composites. Wood and Fiber Science, 37, 643-652 (2005).

[20] Fabiyi J. S., McDonald A. G., Morrell J. J., Freitag C.: Effects of wood species on durability and chemical changes of fungal decayed wood plastic composites. Composites Part A: Applied Science and Manufacturing, 42, 501-510 (2011).

DOI: 10.1016/j.compositesa.2011.01.009

[21] Abu-Sharkh B. F., Hamid H.: Degradation study of date palm fibre/polypropylene composites in natural and artificial weathering: Mechanical and thermal analysis. Polymer Degradation and Stability, 85, 967973 (2004).

DOI: 10.1016/j.polymdegradstab.2003.10.022

[22] Fabiyi J. S., McDonald A. G.: Physical morphology and quantitative characterization of chemical changes of weathered PVC/pine composites. Journal of Polymers and the Environment, 18, 57-64 (2010). DOI: $10.1007 / \mathrm{s} 10924-009-0152-9$

[23] Pattamasattayasonthi N., Chaochanchaikul K., Rosarpitak V., Sombatsompop N.: Effects of UV weathering and $\mathrm{CeO}_{2}$-based coating layer on the mechanical and structural changes of wood/PVC composites. Journal of Vinyl and Additive Technology, 17, 9-16 (2011). DOI: $10.1002 / \mathrm{vnl} .20246$

[24] Sombatsompop N., Taptim K., Chaochanchaikul K., Thongpin C., Rosarpitak V.: Improvement of structural and thermal stabilities of PVC and Wood/PVC composite by $\mathrm{Zn}$ and $\mathrm{Pb}$ stearates, and zeolite. Journal of Macromolecular Science Part A: Pure and Applied Chemistry, 45, 534-541 (2008). DOI: $10.1080 / 10601320802100572$

[25] Xiang X., Chen S., Zhang J., Chai R.: Effect of the combination of a benzophenone-type ultraviolet absorber with thermal stabilizers on the photodegradation of poly(vinyl chloride). Journal of Vinyl and Additive Technology, 16, 23-32 (2010). DOI: $10.1002 / \mathrm{vnl} .20222$

[26] ASTM G154: Standard practice for operating fluorescent light apparatus for UV exposure of nonmetallic materials (2006).

[27] Rabek J. F.: Photostabilization of polymers: Principles and applications. Elsevier, New York (1990).

[28] Anton-Prinet C., Dubois J., Mur G., Gay M., Audouin L., Verdu J.: Photoageing of rigid PVC-II. Degradation thickness profiles. Polymer Degradation and Stability, 60, 275-281 (1998).

DOI: 10.1016/S0141-3910(97)00077-3 
[29] Andrady A. L., Hamid S. H., Hu X., Torikai A.: Effects of increased solar ultraviolet radiation on materials. Journal of Photochemistry and Photobiology B: Biology, 46, 96-103 (1998).

DOI: 10.1016/S1011-1344(98)00188-2

[30] Real L. P., Gardette J-L., Rocha A. P.: Artificial simulated and natural weathering of poly(vinyl chloride) for outdoor applications: The influence of water in the changes of properties. Polymer Degradation and Stability, 88, 357-362 (2005).

DOI: $10.1016 /$ j.polymdegradstab.2004.11.012
[31] Rabek J. F., Rånby B., Östensson B., Flodin P.: Oxidation of polyene structures in poly(vinyl chloride) by molecular oxygen and singlet oxygen. Journal of Applied Polymer Science, 24, 2407-2413 (1979). DOI: $10.1002 / a p p .1979 .070241209$

[32] Chaochanchaikul K., Jayaraman K., Rosarpitak V., Sombatsompop N.: Influence of lignin content on photodegradation in wood/HDPE composites under UV weathering. BioResources, 7, 38-55 (2012). 